\title{
nature
}

\section{Lessons from Huntingdon}

The virtual destruction of an animal-testing company by activists and terrorists has highlighted again the power of fundamentalist minorities. Industry and government have failed to respond adequately to the public challenge.

A company that sets itself up in Britain, one of the most animalprotective nations in the world, to expose tens of thousands of animals every year to tests that cause pain or death might be said to be asking for trouble. But such activities are not only legal, they are also an unpleasant necessity.

If, however, such a company is short-sighted enough to conduct its tests in a manner that is both cruel and illegal, it fully deserves to lose the backing of customers, investors and the public. The pressures on the animal-testing contractor Huntingdon Life Sciences (HLS) from animal-rights activists appear to have been stimulated by a succession of undercover investigations during the past 10 years which revealed, most powerfully in a television broadcast in 1997, that the firm had much to answer for.

Talk to some of its customers today, and you find their faith in its practices has been restored by its changed management. However, the number of its customers has diminished, thanks to a relentless, vicious and clever campaign that followed on the heels of a previous campaign which had succeeded in closing down a supplier of cats used in biomedical research. A look at the website of the group Stop Huntingdon Animal Cruelty (SHAC) (http://www.freespeech.org/sharelist/ SHACTEMP/) reveals the continuity of the campaign, while a read of its "demo reports" gives a taste of the attitudes behind the demonstrations: "The timing was perfect. As the staff from HLS were leaving work on Thursday evening, over thirty animal rights activists besieged the site. They surrounded a car that was half way out of the gateway. The three police officers who were on the scene could do nothing but stand by and watch as the car was forced back into HLS and security guards struggled to close the gate. ... It took over 45 minutes before enough police reinforcements arrived to enable the workers to leave in relative safety. However, a separate group of activists were waiting further down the road and ambushed some of the workers. Several of the workers had their car windows smashed. ... Later on in the evening people paid a visit to [name deleted], head animal technician at HLS' Occold lab to remind him to have a filthy Christmas and to advise him to leave HLS. We think he got the message!"

\section{Illegal tactics}

The tactics described have ranged from breaking into the factories of HLS's suppliers, distributing leaflets to the neighbours of HLS workers, and threatening HLS investors and bankers in the United Kingdom and North America. Illegal tactics by rogue activists, disowned by SHAC, are described on its website by means of quotes from news stories - for example, an HLS executive being temporarily blinded by an unidentified substance thrown at him.

To seek a rational debate with those behind the protests is to miss an essential point. Although the anti-HLS campaign appears to be well focused and have clear originators, it has attracted some, again disowned by SHAC, who belong to what is more a movement than an organization, referred to as the Animal Liberation Front, which began in 1976 — some of its self-nominated fundamentalist 'members' believe that animals are more deserving of protection than people, and that "to drink milk is to have blood on your lips".
A good portrait of the Animal Liberation Front's 'members' can be found at http://www.guardianunlimited.co.uk/Archive/Article/ $0,4273,3824140,00 \cdot h t m l$

Side by side with these terrorists are people who have far less extreme views, but who are appalled by Huntingdon's past reported misdemeanours. Whatever the type of anti-HLS campaigner, their style in television debates has been well calculated: avoid specifics, repeat propaganda statements as a mantra and thereby trade on the gut feelings of the public against animal testing.

\section{Government intervention}

The UK government has belatedly woken up to the effectiveness of such tactics, which have brought HLS to the brink of extinction. Pressure from the government has helped HLS find last-minute, albeit anonymous, financial help. History suggests that, had it not been for the fact that the company's demise would have sent a damaging signal about Britain as a place in which to do biology-based business, the British government would not have lifted a finger.

The campaigners would have moved on to another target had HLS folded, but as it is, the activists have sworn to keep the pressure on the company's customers and to track down its new anonymous US investors. As such actions continue, the mass media, having appropriately broadcast the past shortcomings of HLS, need to ensure that the true character of these campaigns and the people behind them are also kept in the public eye.

Furthermore, the pharmaceutical industry needs to rethink its public tactics - unless it intends to concentrate future efforts in the many countries where the regulation of animal research is more lax than in the United Kingdom. But assuming that the industry still wishes to work in Britain, it should adopt a higher profile, starting with the Internet. The web is full of information about animal cruelty, real and alleged, but informed responses to specific campaigns are sparse. Some organizations - not least the Research Defence Society - offer general facts and figures. But it is hard to find any statement from industry - the websites of the big companies and of the Association of the British Pharmaceutical Industry appear to provide no information that might help the defenders of animal testing in their cause. The SHAC website includes letters to SHAC from Merck Pharmaceuticals UK and from Servier UK stating that they are not contracting HLS to test their products. If terrorist tactics were responsible for their decisions, the companies should work with the government to obtain support and reverse them.

Finally, the research community and its regulators, in and outside Britain, should ask themselves what the lessons of these events are for the conduct of animal testing and research. There is a need to maintain a higher profile about the continuing progress in the refinement, reduction and replacement of the use of animals. Researchers dependent on animals - together with their funding agencies — should also work to overcome the inertia of experience and expertise, and aim to keep animal testing and models as far down the animal kingdom's hierarchy of organismal complexity and cognitive ability as their scientific goals allow. 